\title{
Lanthanum chloride enhances the photosynthetic characteristics and increases konjac glucomannan contents in Amorphophallus sinensis Belval
}

\author{
X.X. LI*, B. YU*, Y.Y. DONG*, L.S. WANG*, S.L. ZHANG*, H.Y. SHANGGUAN**, Z.H. HE*, \\ X.M. LUO*, and P.F. LAI*,+ \\ College of Pharmaceutical Science, Zhejiang Chinese Medical University, Hangzhou, 310053 Zhejiang, China* \\ Hangzhou Sochi Technology Co. Ltd., Hangzhou, 310000 Zhejiang, China**
}

\begin{abstract}
Lanthanum (La) has been used as agricultural inputs in order to enhance yield and improve crop quality. However, little is known about the effect of La on the photosynthesis and growth of Amorphophallus sinensis, a worldwide food source. The effects of $\mathrm{La}$ on the photosynthetic and chlorophyll fluorescence parameters, photosynthetic pigments, corm yield, and konjac glucomannan (KGM) of Amorphophallus sinensis were investigated via field experiments. The leaves were sprayed with different concentrations of $\mathrm{LaCl}_{3}\left(20,80,160\right.$, and $\left.240 \mathrm{mg} \mathrm{L}^{-1}\right)$. The results exhibited an increasing effect of $\mathrm{LaCl}_{3}$ on photosynthetic rate, stomatal conductance, intercellular $\mathrm{CO}_{2}$ concentration, chlorophyll fluorescence parameters, photosynthetic pigments, corm yield, and KGM, when concentration was between 20 and $240 \mathrm{mg} \mathrm{L}^{-1}$, and the most effective concentration was $160 \mathrm{mg} \mathrm{L}^{-1}$. Therefore, moderate $\mathrm{LaCl}_{3}$ concentration may increase yield of Amorphophallus sinensis by enhancing the photosynthetic efficiency, increasing the corm yield, and KGM contents.
\end{abstract}

Additional key words: chlorophyll content; gas-exchange parameters; rare element.

\section{Introduction}

Lanthanum (La), is a metallic element belonging to the light rare earth elements (REEs) group, which has been widely applied in medicine, chemical engineering, new materials, and the electronic aerospace industry due to its unique physical and chemical properties (Zhao et al. 2008, Humphries 2013, Massari and Ruberti 2013). Moreover, La has been used as agricultural fertilizer in Asia, Europe, and South America in order to enhance yield and improve crop quality (Redling 2006, Wang et al. 2012). Previous research showed that appropriate La concentration has positive effects on plant physiology, crop quality, and plant resistance to disease and stress (Hu et al. 2004, Peng and Zhou 2009b, Ippolito et al. 2010, Wang et al. 2014, Yang et al. 2014). For example, $11.33 \mathrm{mg}\left(\mathrm{LaCl}_{3}\right) \mathrm{L}^{-1}$ increased net photosynthetic rate $\left(P_{\mathrm{N}}\right)$ and stomatal conductance in rice (Wang et al. 2014), $20 \mathrm{mg}\left(\mathrm{LaCl}_{3}\right) \mathrm{L}^{-1}$ reduced injuries caused by enhanced UV-B radiation in soybean seedlings (Yang et al. 2014), and $100 \mathrm{mg}\left(\mathrm{LaCl}_{3}\right) \mathrm{L}^{-1}$ increased growth, soluble sugar content, and vitamin $\mathrm{C}$ contents in Chinese cabbage (Ma et al. 2014). These different responses were related to the dose, application methods, and growth medium, as well as plant species and developmental stage (von Tucher et al. 2005, Zhang et al. 2013, de Oliveira et al. 2015, Turra et al. 2015). However, high La concentrations may induce also negative responses of the plant. For instance, high La concentration (> 279 $\mathrm{mg} \mathrm{L}^{-1}$ ) decreased growth, root function, and nutritional status of the maize and mung bean (Diatloff et al. 2008). Furthermore, La promoted the secondary metabolites accumulation in plants (Peng and Zhou 2009b). $\mathrm{LaCl}_{3}$ (20 $\mathrm{mg} \mathrm{L}^{-1}$ ) promoted accumulation of the flavonoid to protect soybean seedlings under UV-B radiation (Peng and Zhou 2009a). $\mathrm{LaCl}_{3}\left(20-80 \mu \mathrm{mol} \mathrm{L} \mathrm{L}^{-1}\right)$ promoted the leaf photosynthesis and accumulated the artemisinin in Artemisia annua (Zhou et al. 2010).

Konjac, Amorphophallus sinensis Belval, has been used and cultivated as a traditional medicine and a food source in China for more than 1,000 years. Konjac glucomannan (KGM) is a major component derived from the konjac corm, which consists of a polysaccharide chain of beta-D glucose and beta-D-mannose with attached acetyl groups in a molar ratio of 1:1.6 with beta-1,4 linkages (Shimahara

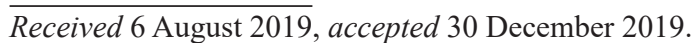

${ }^{+}$Corresponding author; e-mail: pingfan_lai@sina.cn

Abbreviations: Car - carotenoids; Chl - chlorophyll; $C_{\mathrm{i}}$ - intercellular $\mathrm{CO}_{2}$ concentration; DM - dry mass; FM - fresh mass; $\mathrm{F}_{\mathrm{v}} / \mathrm{F}_{\mathrm{m}}-$ the maximal efficiency of PSII photochemistry; $g_{\mathrm{s}}$ - stomatal conductance; KGM - konjac glucomannan; NPQ - the nonphotochemical quenching; $P_{\mathrm{N}}-$ net photosynthetic rate; $\mathrm{q}_{\mathrm{P}}$ - photochemical quenching; REEs - rare earth elements; $\Phi_{\mathrm{PSII}}-$ the effective efficiency of PSII photochemistry.

Acknowledgments: This work was supported by the Science Technology Department of Zhejing Province (2014C33213), the Fourth National Survey on Chinese material medical resources (Zhejing Province) [17-21206, (2018) 132], and the Open Fund of Zhejiang Chinese Medical University (Yao2016013). We appreciate Fengzhi Cui, Xiaoyan Zhao, and Fenyao Zhang for linguistic assistance during the preparation of this manuscript. 
et al. 1975, Katsuraya et al. 2003). Over the last few decades, KGM has been introduced to the United States and Europe, as a food additive in the treatment of obesityrelated dyslipidemia and diabetes due to its effectiveness in lowering blood cholesterol and sugar level, promote intestinal activity and immune function (Vuksan et al. 2001, Keithley and Swanson 2005, Zhang et al. 2005, Vasques et al. 2008, Chen et al. 2019). Moreover, because of its good biocompatibility and biodegradable activity, the applications of KGM and its derivatives has been extended greatly in various fields, such as pharmaceutical, biotechnical, fine chemical industry, and so on (Wang and He 2002, Chen et al. 2004, Devaraj et al. 2019). However, few studies were carried out to investigate cultivation of konjac (Cui 2009), especially, the effects of plant growth regulating substances on growth and phytochemical content of konjac. With the increasing quantity demand for KGM, the konjac production was in short of supply. It is important to increase the corm yield and the KGM of konjac in agricultural applications.

The objectives of our study were to investigate the effects of $\mathrm{LaCl}_{3}$ with different concentrations on the photosynthetic and chlorophyll (Chl) fluorescence parameters, as well as the corm yield and the KGM contents in Amorphophallus sinensis. Our study may help explain the regulatory mechanism for the effect of La on plant photosynthesis and production, and provide a theoretical and practical basis for the high yield cultivation of Amorphophallus sinensis.

\section{Materials and methods}

Study site: The experimental site is located in the Jinhua town of Xiaoshan district (29 50'54"N, $\left.120^{\circ} 04^{\prime} 22^{\prime \prime} \mathrm{E}\right)$, Hangzhou, Zhejiang Province, China. It is in a subtropical monsoon climate region, annual mean temperature is $16.8^{\circ} \mathrm{C}$, and annual mean precipitation is $1,440 \mathrm{~mm}$. The frost-free period is about $248 \mathrm{~d}$. The soil type is acidic red soil. The East Asian rainy season (plum rain season) is from June to July. The heat waves happened occasionally in summer. During this experiment, the heat wave occurred on 22 July 2017 (after $36 \mathrm{~d}$ of treatment), and the highest air temperature was $42.2^{\circ} \mathrm{C}$.

Experimental design: The corms of Amorphophallus sinensis were collected from konjac planting base of Zhejiang Traditional Chinese Medicine University in Pan-an, Zhejiang Province, China. The similar age and height samples $(100 \pm 5 \mathrm{~g})$ were selected and planted in Xiaoshan planting base in April 2017. The soil was mixed with organic fertilizer and grass ash. The randomized complete block design with three replicates was adopted in the study. Each treatment area was $10 \mathrm{~m}^{2}(10 \times 1 \mathrm{~m})$ with 20 plant samples.

Foliage spraying treatment was adopted on 15 June 2017, at the leaf expansion stage of Amorphophallus sinensis (Fig. 1). Four concentrations of La (III) solutions $\left(20,80,160\right.$, and $\left.240 \mathrm{mg} \mathrm{L}^{-1}\right)$ were evenly sprayed on the leaves of Amorphophallus sinensis. At the same time, the same amount of distilled water was used for the control (CK) plants. The solutions were prepared by dissolving the appropriate quantities of $\mathrm{LaCl}_{3} \cdot 7 \mathrm{H}_{2} \mathrm{O}$ (Sigma-Aldrich, USA). After $7 \mathrm{~d}$ of treatment, we began to take photosynthetic measurements. During the whole experimental period, water and field management were taken by designated personnel to avoid water stress.

In the pilot study, we studied the effects of six different concentrations of La solutions (10, 20, 80, 160, 240, and $320 \mathrm{mg} \mathrm{L}^{-1}$ ) on photosynthesis in Amorphophallus sinensis in seven consecutive days. The results showed no significant difference between $10 \mathrm{mg} \mathrm{L}^{-1}$ treatment and $20 \mathrm{mg} \mathrm{L}^{-1}$ treatment. However, with $320 \mathrm{mg} \mathrm{L}^{-1}$ treatment, the photosynthesis in Amorphophallus sinensis was significantly inhibited and resulted in plant damage. Meanwhile, the photosynthesis showed a plateau after $5 \mathrm{~d}$ of La treatment. Combined with the literature (Ma et al.

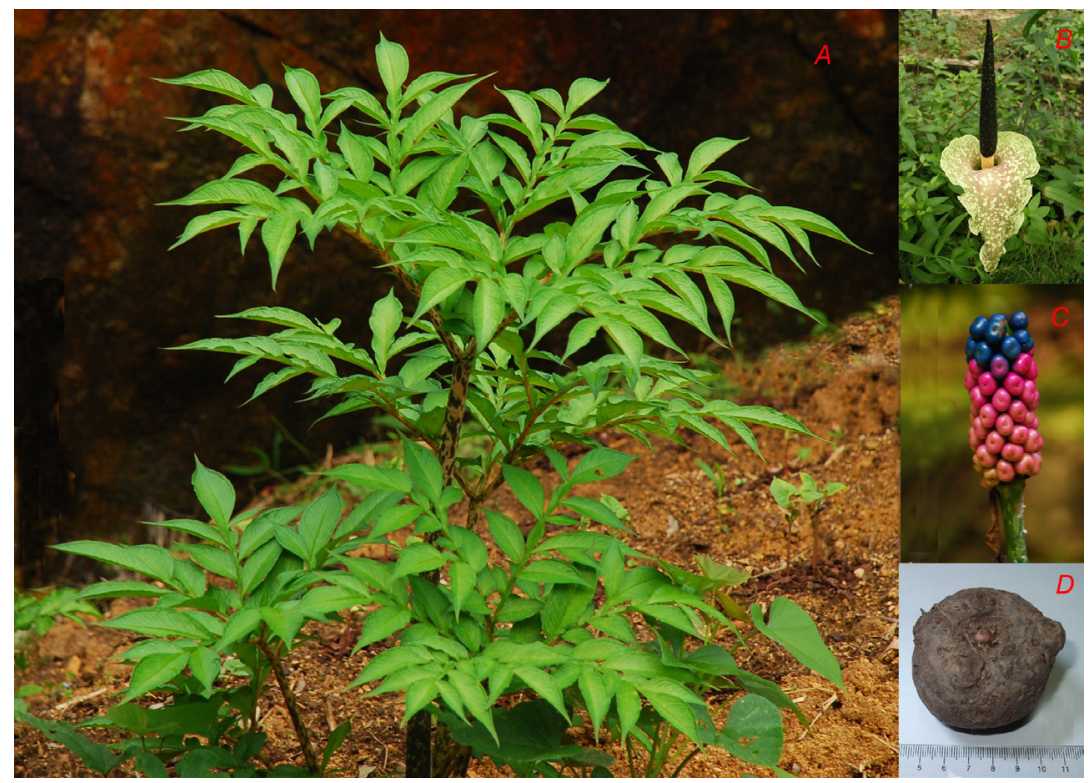

Fig. 1. Amorphophallus sinensis phenotype. $(A)$ complete stool; $(B)$ flower; $(C)$ fructus; (D) corm. 
2017), we choose the four concentrations of La solutions $\left(20,80,160\right.$, and $\left.240 \mathrm{mg} \mathrm{L}^{-1}\right)$ in our study.

The gas-exchange and $\mathrm{Chl}$ fluorescence were measured with the LI-6400XT portable photosynthesis system ( $L I-C O R$, Lincoln, NE, USA) equipped with a fluorescence chamber (6400-40). Based on the results of our pilot study and literature (Ma et al. 2017), the interval between measurements should be $7 \mathrm{~d}$ at minimum. Due to the conflicting measurement schedule among three research projects, we did not have enough LI-6400XT portable instruments to take photosynthetic measurement during the whole experimental period. Therefore, gas-exchange parameters $\left(P_{\mathrm{N}}, g_{\mathrm{s}}\right.$, and $\left.C_{\mathrm{i}}\right)$ after 7,14 , and $21 \mathrm{~d}$ of the treatment were measured. While the Chl fluorescence was measured after $7,14,21,36$, and $60 \mathrm{~d}$ of treatment. In each treatment, six healthy and fully expanded leaves were chosen to measure photosynthetic and $\mathrm{Chl}$ parameters between 8:30-11:30 $\mathrm{h}$ in the morning. The intrinsic fluorescence $\left(\mathrm{F}_{0}\right)$ and the maximum fluorescence $\left(\mathrm{F}_{\mathrm{m}}\right)$ were measured at night (19:30 h).

The photosynthetic parameters included net photosynthetic rate $\left(P_{\mathrm{N}}\right)\left[\mu \mathrm{mol}\left(\mathrm{CO}_{2}\right) \mathrm{m}^{-2} \mathrm{~s}^{-1}\right]$, the stomatal conductance $\left(g_{\mathrm{s}}\right)\left[\mathrm{mmol}\left(\mathrm{H}_{2} \mathrm{O}\right) \mathrm{m}^{-2} \mathrm{~s}^{-1}\right]$, the intercellular $\mathrm{CO}_{2}$ concentration $\left(C_{\mathrm{i}}\right)\left[\mu \mathrm{mol}\left(\mathrm{CO}_{2}\right) \mathrm{mol}^{-1}\right], \mathrm{F}_{\mathrm{s}}, \mathrm{F}_{0}^{\prime}$, and $\mathrm{F}_{\mathrm{m}}{ }^{\prime}$. Along with photosynthetic measurements, other environmental conditions were also monitored. The $\mathrm{CO}_{2}$ concentration was $380 \mu \mathrm{mol} \mathrm{mol}{ }^{-1}$ and the air volume flow was $300 \mu \mathrm{mol} \mathrm{s}{ }^{-1}$. The air temperature was $30^{\circ} \mathrm{C}$ and relative humidity was $65 \%$. The PAR intensity was $800 \mu \mathrm{mol}$ (photon) $\mathrm{m}^{-2} \mathrm{~s}^{-1}$.

The maximal efficiency of PSII photochemistry $\left(\mathrm{F}_{\mathrm{v}} / \mathrm{F}_{\mathrm{m}}\right)$, the effective efficiency of PSII photochemistry $\left(\Phi_{\mathrm{PSII}}\right)$, photochemical quenching $\left(\mathrm{q}_{\mathrm{P}}\right)$, and nonphotochemical quenching (NPQ) were calculated using following equations: $\mathrm{F}_{\mathrm{v}} / \mathrm{F}_{\mathrm{m}}=\left(\mathrm{F}_{\mathrm{m}}-\mathrm{F}_{0}\right) / \mathrm{F}_{\mathrm{m}}, \Phi_{\mathrm{PSII}}=\left(\mathrm{F}_{\mathrm{m}}{ }^{\prime}-\mathrm{F}_{\mathrm{s}}\right) / \mathrm{F}_{\mathrm{m}}{ }^{\prime}$, $\mathrm{q}_{\mathrm{P}}=\left(\mathrm{F}_{\mathrm{m}}{ }^{\prime}-\mathrm{F}_{\mathrm{s}}\right) /\left(\mathrm{F}_{\mathrm{m}}{ }^{\prime}-\mathrm{F}_{0}{ }^{\prime}\right), N P Q=\left(\mathrm{F}_{\mathrm{m}}-\mathrm{F}_{\mathrm{m}}{ }^{\prime}\right) / \mathrm{F}_{\mathrm{m}}{ }^{\prime}$.

Photosynthetic pigment content: In each treatment, six healthy and fully expanded leaves were chosen to measure pigment content. Chlorophylls (Chl) and carotenoids (Car) content was extracted with $80 \%$ acetone, and absorbances (A) at 470, 647, and $663 \mathrm{~nm}$ were recorded with a spectrophotometer (UV-6100, Shanghai Metash Instruments, China). The contents of total Chl and Car were determined according to Lichtenthaler (1987).

Corm yield and the konjac glucomannan (KGM) content assay: In each treatment, we took 20 corms to estimate a corm yield and KGM content. At the end of the experiment, the corms were collected and dried in an air oven at $80^{\circ} \mathrm{C}$ until reached a constant mass to obtain dry mass. The content of KGM was calculated according to the method of 3,5-dinitrosalicylic acid colorimetric assay, which has been adopted by the Chinese Ministry of Agriculture for the classification of konjac flour (Liu et al. 2002).

Statistical analysis: The data analyses were performed by SPSS 17.0. one-way analysis of performance (ANOVA) and Duncan's multiple range tests at the 5\% level of significance were used for multiple comparisons. Pearson's correlation was used to investigate the relationships among the variables.

\section{Results}

Gas-exchange parameters: After 7, 14, and $21 \mathrm{~d}$ of treatments, the $\mathrm{LaCl}_{3}$ treatment significantly increased $P_{\mathrm{N}}$ from 4.17 to $12.06 \mu \mathrm{mol}\left(\mathrm{CO}_{2}\right) \mathrm{m}^{-2} \mathrm{~s}^{-1}$ (Fig. 2). The largest value was observed at $160 \mathrm{mg}\left(\mathrm{LaCl}_{3}\right) \mathrm{L}^{-1}$. The increasing effect

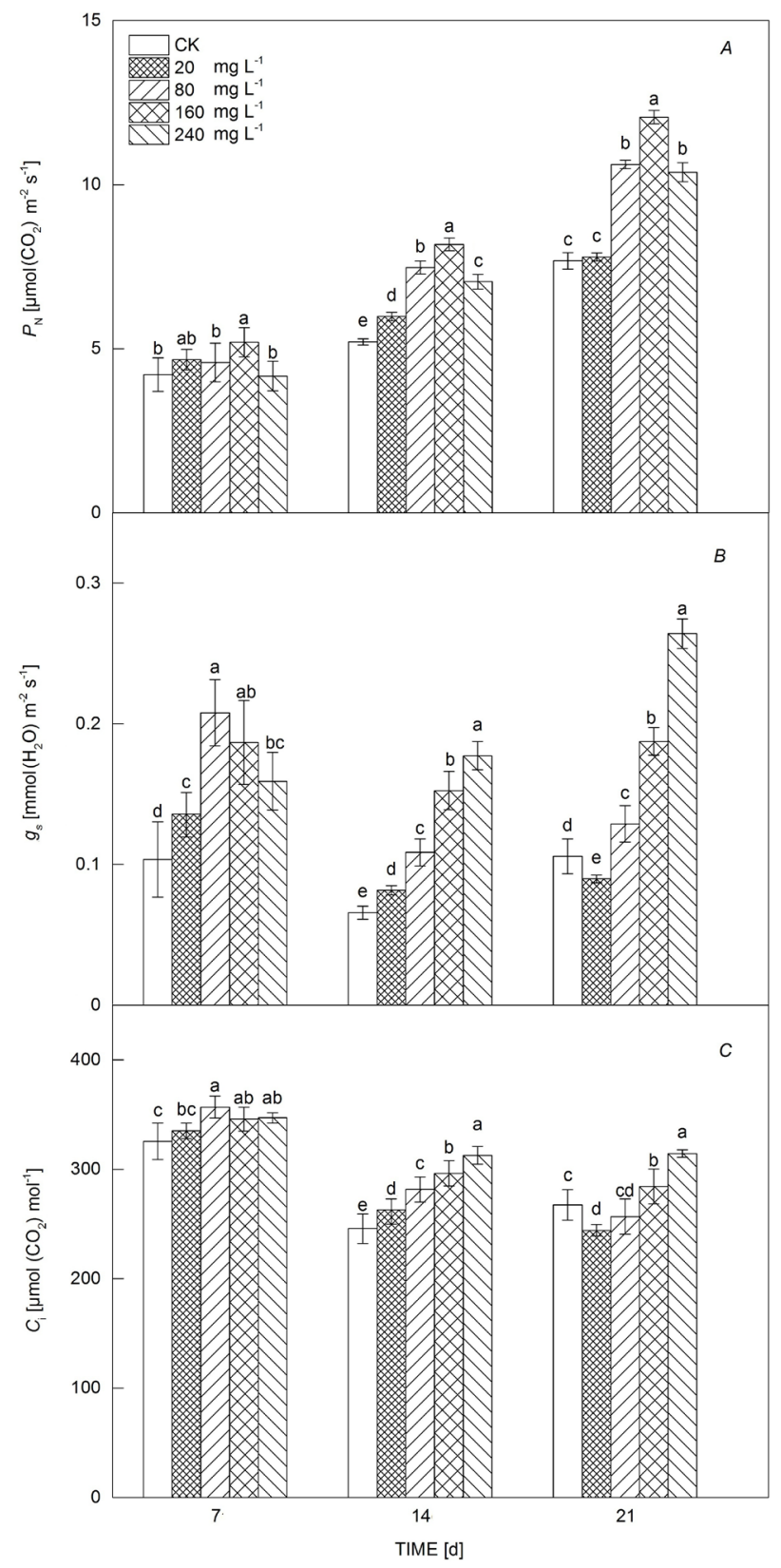

Fig. 2. Effects of $\mathrm{LaCl}_{3}$ on $(A) P_{\mathrm{N}}-$ net photosynthetic rate, $(B) g_{\mathrm{s}}$ - stomatal conductance, and $(C) C_{\mathrm{i}}$ - intercellular $\mathrm{CO}_{2}$ concentration in Amorphophallus sinensis. Means $\pm \mathrm{SD}$ of six samples. Different lowercase letters indicate significant differences between treatments $(P<0.05)$. 
correlates with the concentration. Compared with $\mathrm{CK}$, the four treatments significantly stimulated $g_{\mathrm{s}}$ after 7,14 , and $21 \mathrm{~d}$ of spraying. The magnitude of the effect again correlated with the concentration, and ranged from 0.07 to $0.26 \mathrm{mmol}\left(\mathrm{H}_{2} \mathrm{O}\right) \mathrm{m}^{-2} \mathrm{~s}^{-1}$. Similar pattern was also found in $C_{\mathrm{i}}$.

Photosynthetic pigment content: After 7, 14, 21, and $36 \mathrm{~d}$ of treatment, the Chl content increased in all four treatments compared with $\mathrm{CK}$ and the highest value was at $160 \mathrm{mg}\left(\mathrm{LaCl}_{3}\right) \mathrm{L}^{-1}$ (Fig. 3). The increasing effect correlates positively with the $\mathrm{LaCl}_{3}$ concentration. However, an inconsistent pattern appeared after $60 \mathrm{~d}$ of treatment. The range of Chl content was between 1.06 and $2.26 \mathrm{mg}$ $\mathrm{g}^{-1}(\mathrm{FM})$. Meanwhile, the trend of the Car was similar to that of Chl except after $21 \mathrm{~d}$ of treatment. The Car content ranged from 0.23 to $0.48 \mathrm{mg} \mathrm{g}^{-1}(\mathrm{FM})$ and the most significant effect was also found at $160 \mathrm{mg}\left(\mathrm{LaCl}_{3}\right) \mathrm{L}^{-1}$ except for $21 \mathrm{~d}$ of treatment.

Chl fluorescence: Concerning $\mathrm{F}_{\mathrm{v}} / \mathrm{F}_{\mathrm{m}}$, the direction and magnitude of $\mathrm{LaCl}_{3}$ treatment effect depended on the concentration (Fig. 4A). For example, a decreasing trend was found after $36 \mathrm{~d}$ of treatment, while the increasing effect was observed at the beginning of treatments. The decrease was between 0.57 and 0.70 . Similar pattern was also observed in $\Phi_{\mathrm{PSII}}$ (Fig. $4 B$ ). The decreasing trend was found after $36 \mathrm{~d}$ treatment, ranging from 0.03 to 0.05 . There was no consistent pattern for $\mathrm{q}_{\mathrm{p}}$ (Fig. 4C). The highest value of $\mathrm{q}_{\mathrm{P}}$ occurred at $160 \mathrm{mg}\left(\mathrm{LaCl}_{3}\right) \mathrm{L}^{-1}$, and decreased after 36 and $60 \mathrm{~d}$ of treatments, ranging from 0.11 to 0.22 . However, after 14,21 , and $60 \mathrm{~d}$, the NPQ in all $\mathrm{LaCl}_{3}$ treatments decreased by different degree. The lowest value after $60 \mathrm{~d}$ was from 0.10 to 0.23 (Fig. $4 D$ ).

Correlation analysis of different indexes: $P_{\mathrm{N}}$ positively correlated with Car, Chl, $g_{\mathrm{s}}, \Phi_{\mathrm{PSII}}, \mathrm{q}_{\mathrm{P}}$, and $\mathrm{F}_{\mathrm{v}} / \mathrm{F}_{\mathrm{m}}$, and negatively correlated with $C_{\mathrm{i}}$ and NPQ (Table 1$)$. The $g_{\mathrm{s}}$ negatively correlated with $C_{\mathrm{i}}$ and NPQ, and positively correlated with $\mathrm{F}_{\mathrm{v}} / \mathrm{F}_{\mathrm{m}}$. In addition, $\mathrm{F}_{\mathrm{v}} / \mathrm{F}_{\mathrm{m}}$ was positively correlated with $\Phi_{\mathrm{PSII}}, \mathrm{q}_{\mathrm{P}}$, and Car. $\Phi_{\mathrm{PSII}}$ was positively correlated with qp and Car, but negatively correlated with NPQ. Car was positively correlated with $\mathrm{q}_{\mathrm{p}}$ and Chl, but negatively correlated with NPQ.

Corm yield and the KGM content: Compared with CK, all treatments significantly increased the corm yield and KGM (Fig. 5). The highest increase was observed after $160 \mathrm{mg} \mathrm{L}^{-1}$ treatment by 18.4 and $77.4 \%$, respectively. However, when the concentration of $\mathrm{LaCl}_{3}$ increased from 160 to $240 \mathrm{mg} \mathrm{L}^{-1}$, the corm yield and the content of KGM decreased. Compared to the $160 \mathrm{mg} \mathrm{L}^{-1}$ treatment, the corm yield and KGM content at $240 \mathrm{mg} \mathrm{L}^{-1}$ decreased by 6.8 and $33.4 \%$, respectively.

\section{Discussion}

La promotes photosynthetic activity: Our results showed that $\mathrm{LaCl}_{3}$ significantly increased $P_{\mathrm{N}}$ and the peak value was observed at $160 \mathrm{mg} \mathrm{L}^{-1}$. Meanwhile, the enhancing effect correlated with $\mathrm{LaCl}_{3}$ concentration (Fig. 2). Similar pattern was also observed in the content of Chl and Car (Fig. 3). Photosynthetic pigments are one of the important factors for photosynthesis as their compositions and contents directly affected the photosynthetic efficiency (Rathore and Jasrai 2013, Qiu et al. 2019). The correlation analysis also revealed that $P_{\mathrm{N}}$ positively correlated with Car and Chl (Table 1). Previous research observed that a suitable concentration of $\mathrm{La}$ improves the contents of the photosynthetic pigments, accelerates the absorption of the light energy, and then promotes the efficiency of photosynthesis (Rathore and Jasrai 2013, Ma et al. 2017, Rane et al. 2019). Two explanations may account for the effect of La on the photosynthetic pigments. First, an appropriate concentration of La may change the morphology of the external membrane of the chloroplast, which improves the structure of the organelle and leads to a higher concentration of functional nutrients (such as N, P, $\mathrm{Mg}$, etc.) in the chloroplast (Hu et al. 2016a,b). Second, La may substitute $\mathrm{Mg}^{2+}$ during the formation of Chl molecules (Hong et al. 2002, Goecke et al. 2015) and therefore more atoms for the formation of the $\mathrm{Chl}$ molecule could be available in the growth medium. In our study, after $60 \mathrm{~d}$ of treatments, the pigment contents decreased relative to the $\mathrm{CK}$, except for the $160 \mathrm{mg}\left(\mathrm{LaCl}_{3}\right) \mathrm{L}^{-1}$ treatment.

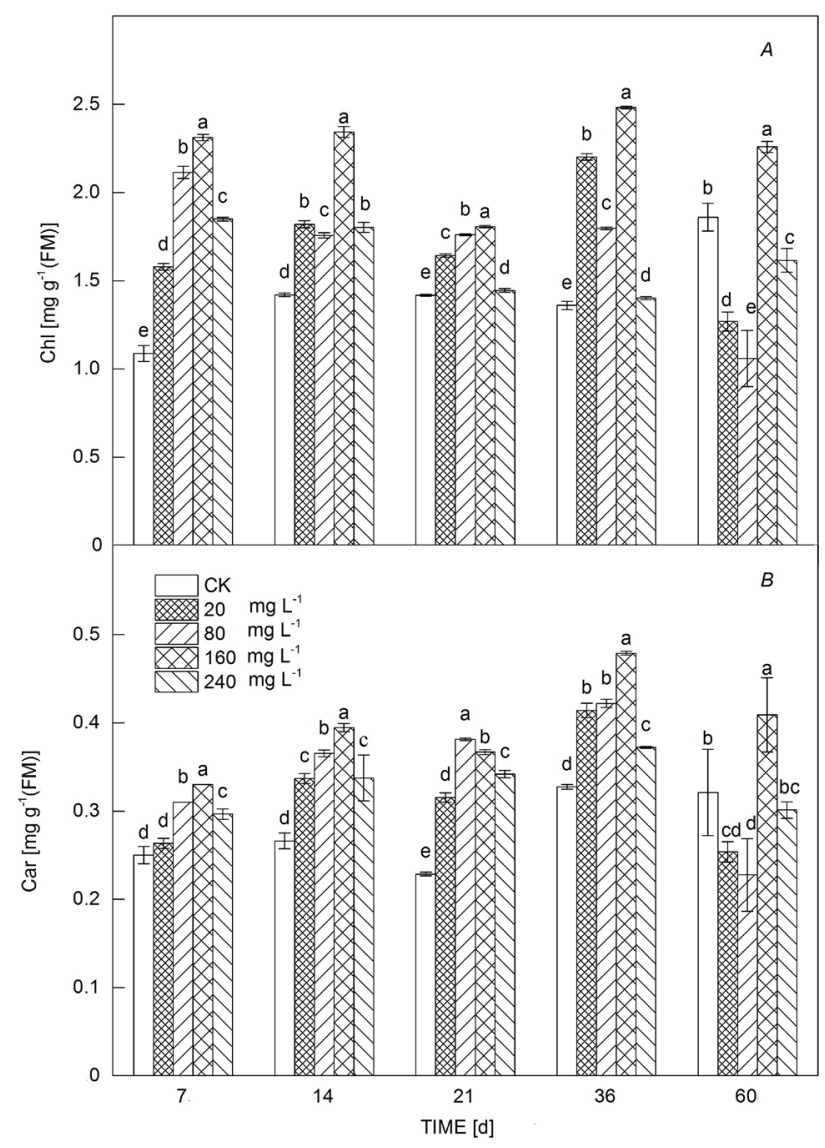

Fig. 3. Effects of $\mathrm{LaCl}_{3}$ on $(A)$ chlorophyll (Chl) content and $(B)$ carotenoids (Car) content in Amorphophallus sinensis. Means \pm SD of six samples. Different lowercase letters indicate significant differences between treatments $(P<0.05)$. 


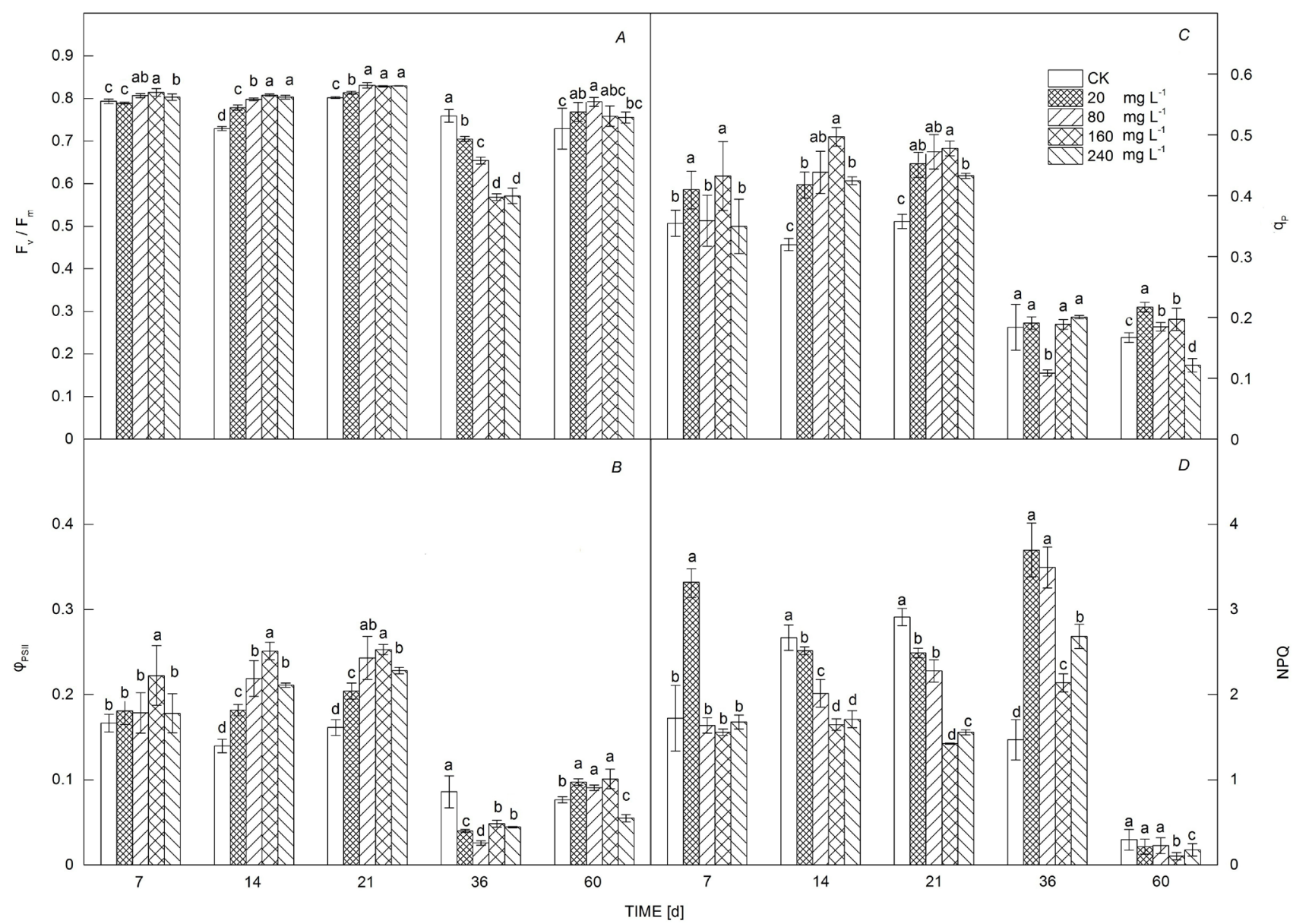

Fig. 4. Effects of $\mathrm{LaCl}_{3}$ on $(A) \mathrm{F}_{\mathrm{v}} / \mathrm{F}_{\mathrm{m}}$ - the maximal efficiency of PSII, $(B) \Phi_{\mathrm{PSII}}-$ the effective efficiency of PSII, $(C) \mathrm{q}_{\mathrm{P}}-$ photochemical quenching, and $(D) \mathrm{NPQ}$ - the nonphotochemical quenching in Amorphophallus sinensis. Means $\pm \mathrm{SD}$ of six samples. Different lowercase letters indicate significant differences between treatments $(P<0.05)$.

Table 1. Pearson's correlation analysis of different indexes of Amorphophallus sinensis. $P_{\mathrm{N}}-$ net photosynthetic rate, $g_{\mathrm{s}}-$ stomatal conductance, $C_{\mathrm{i}}$ - intercellular $\mathrm{CO}_{2}$ concentration, $\mathrm{F}_{\mathrm{v}} / \mathrm{F}_{\mathrm{m}}$ - the maximal efficiency of PSII, $\Phi_{\mathrm{PSII}}-$ the effective efficiency of PSII, $\mathrm{q}_{\mathrm{p}}$ - photochemical quenching, NPQ - the nonphotochemical quenching, Chl - chlorophyll content, Car - carotenoid content. ${ }^{*}$ - significant at $P<0.05,{ }^{* *}$ - significant $P<0.01$.

\begin{tabular}{lccccccccc}
\hline & $P_{\mathrm{N}}$ & $g_{\mathrm{s}}$ & $C_{\mathrm{i}}$ & $\mathrm{F}_{\mathrm{v}} / \mathrm{F}_{\mathrm{m}}$ & $\Phi_{\mathrm{PSII}}$ & $\mathrm{q}_{\mathrm{P}}$ & NPQ & Chl & Car \\
\hline$P_{\mathrm{N}}$ & 1 & & & & & & & \\
$g_{\mathrm{s}}$ & 0.288 & 1 & & & & & & \\
$C_{\mathrm{i}}$ & -0.474 & $-0.638^{*}$ & 1 & & & & & \\
$\mathrm{~F}_{\mathrm{v}} / \mathrm{F}_{\mathrm{m}}$ & $0.619^{*}$ & $0.644^{*}$ & 0.229 & 1 & & & & \\
$\Phi_{\mathrm{PSII}}$ & $0.732^{* *}$ & 0.507 & 0.09 & $0.782^{* *}$ & 1 & & & \\
$\mathrm{q}_{\mathrm{P}}$ & $0.709^{* *}$ & 0.233 & -0.224 & $0.654^{* *}$ & $0.914^{* *}$ & 1 & & \\
$\mathrm{NPQ}$ & -0.211 & $-0.632^{*}$ & -0.442 & -0.485 & $-0.550^{*}$ & -0.241 & 1 & & \\
$\mathrm{Chl}$ & 0.024 & 0.354 & 0.287 & 0.316 & 0.506 & 0.481 & -0.397 & 1 & \\
Car & $0.606^{*}$ & 0.329 & -0.129 & $0.540^{*}$ & $0.885^{* *}$ & $0.839^{* *}$ & $-0.517^{*}$ & $0.624^{*}$ & 1 \\
\hline
\end{tabular}

García-Jiménez et al. (2017) found that the concentrations of total Chl increased in all four varieties of bell pepper (Sven, Zidenka, Sympathy, and Yolo Wonder) seedling exposed to La after $15 \mathrm{~d}$ of treatment. However, different responses were observed after $30 \mathrm{~d}$. Sven and Zidenka seedlings were not affected by La applications. Moreover, in Sympathy and Yolo Wonder seedlings, La reduced the total $\mathrm{Chl}$ concentrations by 44.4 and $17.7 \%$, respectively. Overall, La effects on photosynthetic pigments could be time-dependent. 


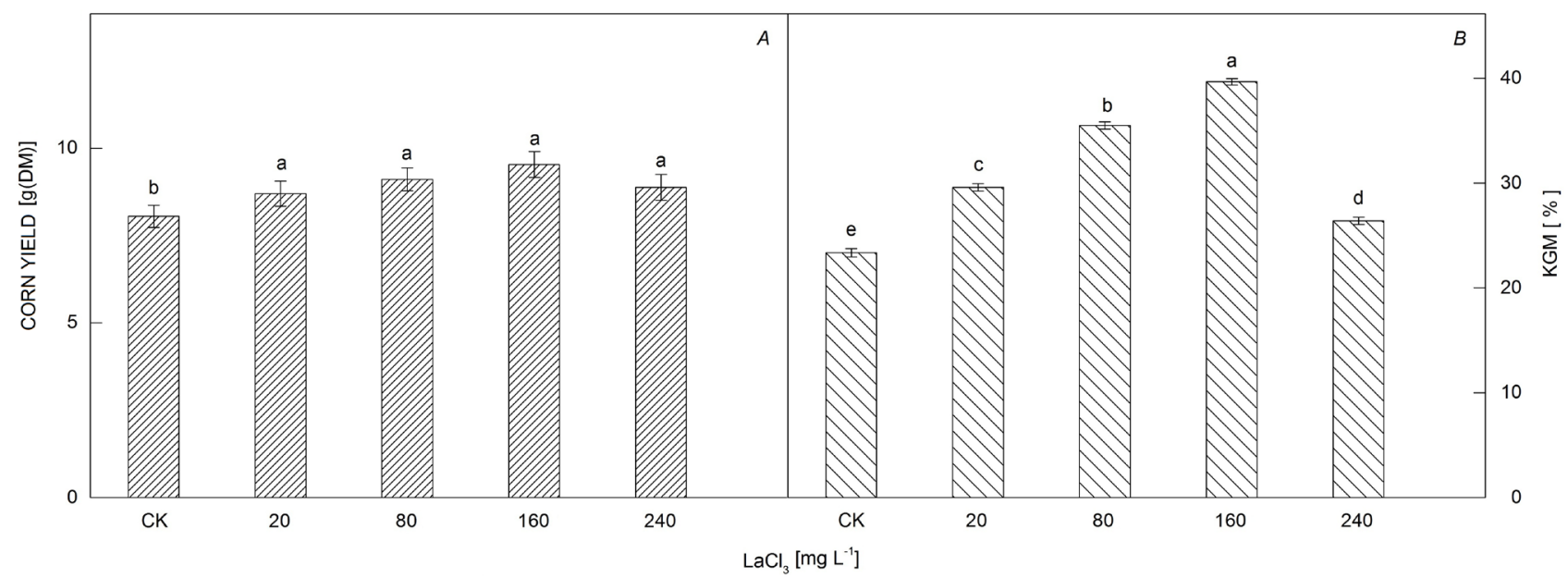

Fig. 5. Effects of $\mathrm{LaCl}_{3}$ on $(A)$ the corm yield and $(B)$ the konjac glucomannan (KGM) contents of Amorphophallus sinensis. Means $\pm \mathrm{SD}$, $n=20$. Different lowercase letters indicate significant differences between treatments $(P<0.05)$.

Effect of La on Chl fluorescence parameters: Chl fluorescence parameters reflect the physiology and mechanism of photosynthesis, which are not only the indicator of the light-use efficiency, but the evaluation index of the plant under environmental stresses (Janka et al. 2013, Guo et al. 2015, Banks 2018, Hanelt 2018, Dai and Shan 2019). $F_{v} / F_{m}$ exhibits the maximal efficiency of PSII photochemistry, which is stable in general. The decrease of $\mathrm{F}_{\mathrm{v}} / \mathrm{F}_{\mathrm{m}}$ may be considered as a potential indicator for environmental stress (Strasser et al. 2000, Meng et al. 2015). The measurement at 7, 14, and $21 \mathrm{~d}$ showed that $\mathrm{F}_{\mathrm{v}} / \mathrm{F}_{\mathrm{m}}, \Phi_{\mathrm{PSII}}$, and $\mathrm{q}_{\mathrm{P}}$ increased in all $\mathrm{LaCl}_{3}$ treatments (Fig. $4 A-C$ ). As to other measurement, the direction and magnitude of the effect of $\mathrm{LaCl}_{3}$ treatment depend on concentration. Moreover, the correlation analysis showed that the $P_{\mathrm{N}}$ was positively correlated with $\mathrm{Car}, \mathrm{F}_{\mathrm{v}} / \mathrm{F}_{\mathrm{m}}, \Phi_{\mathrm{PSII}}$, and $\mathrm{q}_{\mathrm{P}}$ (Table 1). Therefore, a moderate concentration of $\mathrm{LaCl}_{3}$ not only promoted the efficiency of electron capture, transport, and light utilization, it also improved actual photochemical efficiency of PSII and opening rate of the reaction center to enhance the photosynthetic efficiency of Amorphophallus sinensis. Our results are consistent with literature (Liu et al. 2009, Si et al. 2018, Lian et al. 2019). Furthermore, the NPQ measurement at 14 and $21 \mathrm{~d}$ indicated that a moderate concentration of $\mathrm{LaCl}_{3}$ may increase the photosynthetic efficiency by reducing the heat dissipation and enhancing the absorption of the excess excitation energy during the Amorphophallus sinensis growth period (Fig. 4D). In addition, La could also increase the photosynthetic efficiency by stimulating the coupling factors of light reactions (Hong et al. 2002, Redling 2006), improving the activity of Rubisco and chloroplast ATP synthase (Chen et al. 2000, Hong et al. 2005, Zhang et al. 2018).

After $36 \mathrm{~d}$ of treatment, Amorphophallus sinensis experienced the heat wave (the highest air temperature was $42.2^{\circ} \mathrm{C}$ ). Compared with $\mathrm{CK}$, the $\mathrm{F}_{\mathrm{v}} / \mathrm{F}_{\mathrm{m}}, \Phi_{\mathrm{PSII}}$, and $\mathrm{q}_{\mathrm{p}}$ all significantly decreased in all La treatments. For instance, the $\mathrm{F}_{\mathrm{v}} / \mathrm{F}_{\mathrm{m}}$ in all treatments was $0.76(\mathrm{CK}), 0.70$
(20 mg L $\left.{ }^{-1}\right), 0.65\left(80 \mathrm{mg} \mathrm{L}^{-1}\right), 0.57$ (160 $\left.\mathrm{mg} \mathrm{L}^{-1}\right)$, and 0.57 $\left(240 \mathrm{mg} \mathrm{L}^{-1}\right)$, respectively. Significant decreasing trend was found in $\Phi_{\mathrm{PSII}}$ and $\mathrm{q}_{\mathrm{P}}$. For example, compared with previous measurement, $\Phi_{\mathrm{PSII}}$ decreased to 0.05 and $\mathrm{q}_{\mathrm{P}}$ to 0.19 at $160 \mathrm{mg} \mathrm{L}^{-1}$. All these results indicate that $\mathrm{LaCl}_{3}$ treatments of Amorphophallus sinensis were affected by the high temperature. Meanwhile, the contents of photosynthetic pigment (Fig. 3) and NPQ (Fig. 4D) in all La treatments were significantly higher than those in CK. Furthermore, after 24-d recovery, $\mathrm{F}_{\mathrm{v}} / \mathrm{F}_{\mathrm{m}}$ in all La treatments (0.76-0.79) was higher than those of CK (0.73). Other studies indicated that an appropriate $\mathrm{La}$ concentration could improve stress resistance of the plant by promoting the chloroplast structure, increasing the Chl content and $P_{\mathrm{N}}$ and so on (Peng and Zhou 2009b, Ippolito et al. 2010, Wang et al. 2014, Yang et al. 2014, Dai and Shan 2019). In addition, after $60 \mathrm{~d}$ of treatment, Amorphophallus sinensis was in the corm expansion stage and the end of leaves growth (Cui 2009). It also decreased the mean of the $\mathrm{q}_{\mathrm{P}}$, $\Phi_{\text {PSII }}$, and NPQ.

La increases corm yield and KGM: The addition of $\mathrm{LaCl}_{3}\left(20-240 \mathrm{mg} \mathrm{L}^{-1}\right)$ significantly increased the corm yield. The highest yield was observed at $160 \mathrm{mg} \mathrm{L}^{-1}$. This result was similar to that of other previous reports (Liu et al. 2013). Turra et al. (2015) reported that $50 \mathrm{mg}\left(\mathrm{LaCl}_{3}\right) \mathrm{L}^{-1}$ increased biomass and height of Rangpur lime (Citrus limonia Osbeck), but higher concentrations of $400 \mathrm{mg} \mathrm{L}^{-1}$ inhibited growth. In Pseudostellaria heterophylla, $\mathrm{La}\left(\mathrm{NO}_{3}\right)_{3}\left(25-100 \mathrm{mg} \mathrm{\textrm {L } ^ { - 1 }}\right)$ promoted the photosynthesis by increasing the light energy absorption and conversion, enhancing photochemical efficiency as well as alleviating the photoinhibition which improved the growth and root tuber yield of Pseudostellaria heterophylla effectively, whereas higher $\mathrm{La}\left(\mathrm{NO}_{3}\right)_{3}\left(400-700 \mathrm{mg} \mathrm{L}^{-1}\right)$ inhibited the photosynthesis, the growth, and root tuber yield (Ma et al. 2017). In soybean, low La concentrations (0.7-1.4 $\left.\mathrm{mg} \mathrm{L}^{-1}\right)$ stimulated the photosynthetic rate and total $\mathrm{Chl}$ content and led to a higher incidence of binucleate 
cells, resulting in a slight increase in root and shoot biomass. At higher La contents $\left(>2.78 \mathrm{mg} \mathrm{L}^{-1}\right)$, soybean growth was reduced, as a consequence of ultrastructural modifications in the cell wall, thylakoids, and chloroplasts, and the appearance of c-metaphases (de Oliveira et al. 2015). Therefore, it is assumed that La may exert different effects on plant growth depending on the genotype and concentration. Furthermore, appropriate La concentrations have beneficial effects on plant growth and biomass accumulation, which may be attributed to the signal cascades it triggers, including changes in endogenous hormone contents during the reproductive stages, prolonged functional periods of leaves, an improved performance of PSII, a higher velocity of electron transport during photosynthesis, a higher accumulation of mineral nutrients in the chloroplast, an enhanced activity of ATPases, and higher photosynthetic rates (Guo et al. 2012, de Oliveira et al. 2015, Hu et al. 2016a, Cui et al. 2019). However, higher doses of La may unbalance cell homeostasis by causing damage in the external membrane of the chloroplast, decreasing the concentrations of mineral nutrients in this organelle, especially those of $\mathrm{P}, \mathrm{Mg}, \mathrm{K}, \mathrm{Ca}, \mathrm{Mn}$, $\mathrm{Fe}, \mathrm{Ni}, \mathrm{Cu}, \mathrm{Zn}$, and $\mathrm{Mo}$, and disrupting $\mathrm{Chl}$ biosynthesis, which lead to a drastic reduction in photosynthesis, and cause lower growth or even negative impacts on plant performance (Hu et al. 2016b). Additionally, REEs promoted the biosynthesis of the secondary metabolites, such as flavonoids, isoflavones, sesquiterpenoids, and benzyl ethanol glycosides in medicinal plant cells (Yuan et al. 2002, Ouyang et al. 2003, Huang 2006, Zhou et al. 2010, Zhou et al. 2012, Kovaříková et al. 2019). Yuan et al. (1993) found that $20 \mathrm{mg}\left[\mathrm{La}\left(\mathrm{NO}_{3}\right)_{3}\right] \mathrm{kg}^{-1}$ promoted the accumulation of alkaloids of Catharanthus roseus in cell cultures. In our study, $20-240 \mathrm{mg}\left(\mathrm{LaCl}_{3}\right) \mathrm{L}^{-1}$ increased KMG content significantly and $160 \mathrm{mg} \mathrm{L}^{-1}$ had the most increasing effect. However, $240 \mathrm{mg} \mathrm{L}^{-1}$ reduced the contents of $\mathrm{KMG}$, relative to the $160 \mathrm{mg} \mathrm{L}^{-1}$. Similar result was also found in other studies (de Oliveira et al. 2015, Ma et al. 2017). Wang (2009) found that $\mathrm{La}\left(\mathrm{NO}_{3}\right)_{3}$

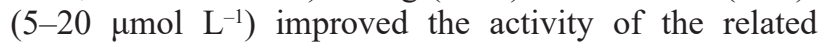
polysaccharide synthetase and promoted the contents of polysaccharide in the Dendrobium huoshanense. However, it had an inhibitory effect with high La concentration (40-80 $\mu \mathrm{mol} \mathrm{L}^{-1}$ ). The high concentration of La accumulated in the cell membrane, resulting in changes in the microstructure and permeability of the cell membrane. Thus, the nutrient transportation was prevented and the synthesis of metabolic products was inhibited.

The study showed an increasing effect of $\mathrm{LaCl}_{3}$ between 20 and $240 \mathrm{mg} \mathrm{L}^{-1}$ on photosynthetic and Chl fluorescence parameters, corm yield, and KGM. The most effective concentration was $160 \mathrm{mg} \mathrm{L}^{-1}$. Therefore, moderate $\mathrm{LaCl}_{3}$ concentration may increase yield of Amorphophallus sinensis by enhancing the photosynthetic efficiency, increasing the corm yield, and KGM contents. Our study may help explain the regulatory mechanism of the effect of La on the photosynthesis and production, and provide a theoretical and practical basis for high yield cultivation of Amorphophallus sinensis.

\section{References}

Banks J.M.: Chlorophyll fluorescence as a tool to identify drought stress in Acer genotypes. - Environ. Exp. Bot. 155: 118-127, 2018.

Chen H., Nie Q., Hu J. et al.: Hypoglycemic and hypolipidemic effects of glucomannan extracted from konjac on type 2 diabetic rats. - J. Agr. Food Chem. 67: 5278-5288, 2019.

Chen W.J., Gu Y.H., Zhao G.W. et al.: Effects of rare earth ions on activity of RuBPcase in tobacco. - Plant Sci. 152: 145-151, 2000.

Chen Y., Zhang L., Lu Y. et al.: Preparation and properties of water-resistant soy dreg/benzyl konjac glucomannan composite plastics. - J. Appl. Polym. Sci. 90: 3790-3796, 2004.

Cui J.M.: [The influence of the copper and chromium stress upon the physiology and biochemistry of Amorphophallus.] Thesis. Pp. 21-22. College of Agronomy and Biotechnology, Yunnan Agricultural University, Kunming 2009. [In Chinese]

Cui W.W., Kamran M., Song Q.H. et al.: Lanthanum chloride improves maize grain yield by promoting photosynthetic characteristics, antioxidants enzymes and endogenous hormone at reproductive stages. - J. Rare Earth 37: 781-790, 2019.

Dai H., Shan C.: Effects of lanthanum on the antioxidant capacity of chloroplasts and chlorophyll fluorescence parameters of maize seedlings under chromium stress. - Photosynthetica 57: 27-31, 2019.

de Oliveira C., Ramos S.J., Siqueira J.O. et al.: Bioaccumulation and effects of lanthanum on growth and mitotic index in soybean plants. - Ecotox. Environ. Safe. 122: 136-144, 2015.

Devaraj R.D., Reddy C.K., Xu B.: Health-promoting effects of konjac glucomannan and its practical applications: A critical review. - Int. J. Biol. Macromol. 126: 273-281, 2019.

Diatloff E., Smith F.W., Asher C.J.: Effects of lanthanum and cerium on the growth and mineral nutrition of corn and mungbean. - Ann. Bot.-London 101: 971-982, 2008.

García-Jiménez A., Gómez-Merino F.C., Tejeda-Sartorius O., Trejo-Téllez L.I.: Lanthanum affects bell pepper seedling quality depending on the genotype and time of exposure by differentially modifying plant height, stem diameter and concentrations of chlorophylls, sugars, amino acids, and proteins. - Front. Plant Sci. 8: 308, 2017.

Goecke F., Jerez C.G., Zachleder V. et al.: Use of lanthanides to alleviate the effects of metal ion-deficiency in Desmodesmus quadricauda (Sphaeropleales, Chlorophyta). - Front. Microbiol. 6: 2, 2015.

Guo B., Xu L.L., Guan Z.J., Wei Y.H.: Effect of lanthanum on rooting of in vitro regenerated shoots of Saussurea involucrata Kar. et Kir. - Biol. Trace Elem. Res. 147: 334-340, 2012.

Guo Y., Zhou Y., Tan J.: Wavelet analysis of pulse-amplitudemodulated chlorophyll fluorescence for differentiation of plant samples. - J. Theor. Biol. 370: 116-120, 2015.

Hanelt D.: Photosynthesis assessed by chlorophyll fluorescence.In: Häder D.P., Erzinger G.S. (ed.): Bioassays: Advanced Methods and Applications. Pp. 169-198. Elsevier, Amsterdam 2018.

Hong F., Liu C., Zheng L. et al.: Formation of complexes of Rubisco-Rubisco activase from $\mathrm{La}^{3+}, \mathrm{Ce}^{3+}$ treatment spinach.Sci. China Ser. B 48: 67-74, 2005.

Hong F., Wei Z., Zhao G.: Mechanism of lanthanum effect on chlorophyll of spinach. - Sci. China Ser. C 45: 166-176, 2002.

Hu H., Wang L., Li Y. et al.: Insight into mechanism of lanthanum (III) induced damage to plant photosynthesis. - Ecotox. Environ. Safe. 127: 43-50, 2016a.

Hu H., Wang L., Zhou Q., Huang X.: Combined effects of 
simulated acid rain and lanthanum chloride on chloroplast structure and functional elements in rice. - Environ. Sci. Pollut. R. 23: 8902-8916, 2016 b.

Hu Z., Richter H., Sparovek G., Schnug E.: Physiological and biochemical effects of rare earth elements on plants and their agricultural significance: a review. - J. Plant Nutr. 27: 183220, 2004.

Huang L.: [Study on establishment of the clone system of Dendrobium densiflorum and Dendrobium exile in vitro and effect of rare earth elements on roots regeneration of Dendrobium densiflorum.] - Thesis. Pp. 39. College of Food Science and Biotechnology Engineering, Hefei University of Technology, Hefei 2006. [In Chinese]

Humphries M.: Rare earth elements: the global supply chain. - In: CRS Report for Congress. Pp. 13-19, CRS Press, Washington 2013.

Ippolito M.P., Fasciano C., d'Aquino L. et al.: Responses of antioxidant systems after exposition to rare earths and their role in chilling stress in common duckweed (Lemna minor L.): A defensive weapon or a boomerang? - Arch. Environ. Con. Tox. 58: 42-52, 2010.

Janka E., Körner O., Rosenqvist E., Ottosen C.O.: High temperature stress monitoring and detection using chlorophyll $a$ fluorescence and infrared thermography in chrysanthemum (Dendranthema grandiflora). - Plant Physiol. Bioch. 67: 87-94, 2013.

Katsuraya K., Okuyama K., Hatanaka K. et al.: Constitution of konjac glucomannan: Chemical analysis and 13C NMR spectroscopy. - Carbohydr. Polym. 53: 183-189, 2003.

Keithley J., Swanson B.: Glucomannan and obesity: A critical review. - Altern. Ther. Health M. 11: 30-34, 2005.

Kovař́ková M., Tomášková I., Soudek P.: Rare earth elements in plants. - Biol. Plantarum 63: 20-32, 2019.

Lian H., Qin C., Zhang L. et al.: Lanthanum nitrate improves phosphorus-use efficiency and tolerance to phosphorusdeficiency stress in Vigna angularis seedlings. - Protoplasma 256: 383-392, 2019.

Lichtenthaler H.K.: Chlorophylls and carotenoids: Pigments of photosynthetic biomembranes. - Method. Enzymol. 148: 350-382, 1987

Liu D., Wang X., Zhang X., Gao Z.: Effects of lanthanum on growth and accumulation in roots of rice seedlings. - Plant Soil Environ. 59: 196-200, 2013.

Liu P.Y., Zhang S.L, Zhu G.H. et al.: Professional standard for the classification, requirements and test methods of konjac flour. Technical report NY/T 494. - In: Chinese Ministry of Agriculture: Agricultural standards of the People's Republic of China. Pp. 7. CMA Press, Beijing 2002.

Liu X.Q., Huang H., Liu C. et al.: Physico-chemical property of rare earths-effects on the energy regulation of photosystem II in Arabidopsis thaliana. - Biol. Trace Elem. Res. 130: 141151, 2009.

Ma J.J., Ren Y.J., Yan L.Y.: Effects of spray application of lanthanum and cerium on yield and quality of Chinese cabbage (Brassica chinensis L.) based on different seasons. Biol. Trace Elem. Res. 160: 427-432, 2014.

Ma Y., Zou H., Gu H. et al.: Stimulatory effect of lanthanum nitrate on the root tuber yield of Pseudostellaria heterophylla via improved photosynthetic characteristics. - J. Rare Earth 35: 610-620, 2017.

Massari S., Ruberti M.: Rare earth elements as critical raw materials: Focus on international markets and futures trategies. - Resour. Policy 38: 36-43, 2013.

Meng L.L., Song J.F., Wen J. et al.: Effects of drought stress on fluorescence characteristics of photosystem II in leaves of Plectranthus scutellarioides. - Photosynthetica 54: 414-421,
2015.

Ouyang J., Wang X., Zhao B. et al.: Effects of rare earth elements on the growth of Cistanche deserticola cells and the production of phenylethanoid glycosides. - J. Biotechnol. 102: 129-134, 2003.

Peng Q., Zhou Q.: Antioxidant capacity of flavonoid in soybean seedlings under the joint actions of rare earth element $\mathrm{La}$ (III) and ultraviolet-B stress. - Biol. Trace Elem. Res. 127: 69-80, 2009a.

Peng Q., Zhou Q.J.: Influence of lanthanum on chloroplast ultrastructure of soybean leaves under ultraviolet-B stress. J. Rare Earth. 27: 304-307, 2009b.

Qiu N.W., Jiang D.C., Wang X.S. et al.: Advances in the members and biosynthesis of chlorophyll family. - Photosynthetica 57: 974-984, 2019.

Rane J., Sharma D., Ekatpure S. et al:: Relative tolerance of photosystem II in spike, leaf, and stem of bread and durum wheat under desiccation. - Photosynthetica 57: 1100-1108, 2019.

Rathore A., Jasrai Y.T.: Growth and chlorophyll levels of selected plants with varying photosynthetic pathways $\left(\mathrm{C}_{3}, \mathrm{C}_{4}\right.$ and CAM). - Int. J. Sci. Eng. Res. 4: 1-4, 2013.

Redling K.: [Rare earth elements in agriculture with emphasis on animal husbandry.] - Doctoral Dissertation. Pp. 87134. Institut für Physiologie, Physiologische Chemie und Tierernährung, Ludwig-Maximilians-Universität München, München 2006. [In Germany]

Shimahara H., Suzuki H., Sugiyama N., Nisizawa K.: Isolation and characterization of oligosaccharides from enzymic hydrolysate of konjac glucomannan. - Agr. Biol. Chem. Tokyo 39: 293-299, 1975.

Si Y., Wang L., Zhou Q., Huang X.: Effects of lanthanum and silicon stress on bio-sequestration of lanthanum in phytoliths in rice seedlings. - Environ. Sci. Pollut. R. 25: 10752-10770, 2018.

Strasser R.J., Srivastava A., Tsimilli-Michael M.: The fluorescence transient as a tool to characterize and screen photosynthetic samples. - In: Yunus M., Pathre U., Mohanty P. (ed.): Probing Photosynthesis: Mechanisms, Regulation and Adaptation. Pp. 445-483. Taylor \& Francis, London 2000

Turra C., De Nadai Fernandes E.A., Bacchi M.A. et al.: Effects of lanthanum on citrus plant. - Int. J. New Tech. Res. 1: 48-50, 2015.

Vasques C.A.R., Rossetto S., Halmenschlager G. et al.: Evaluation of the pharmacotherapeutic efficacy of Garcinia cambogia plus Amorphophallus konjac for the treatment of obesity. - Phytother. Res. 22: 1135-1140, 2008.

von Tucher S., Schmidhalter U.: Lanthanum uptake from soil and nutrient solution and its effects on plant growth. - J. Plant Nutr. Soil Sc. 168: 574-580, 2005.

Vuksan V., Sievenpiper J.L., Xu Z. et al.: Konjac-mannan and American ginsing: Emerging alternative therapies for type 2 diabetes mellitus. - J. Am. Coll. Nutr. 20: 370S-380S, 2001.

Wang C., Luo X., Tian Y. et al.: Biphasic effects of lanthanum on Vicia faba L. seedlings under cadmium stress, implicating finite antioxidation and potential ecological risk. Chemosphere 86: 530-537, 2012.

Wang K.: [Study on cell growth and polysaccharide production regulated by rare earth elements in suspension cultures of protocorm-like bodies from Dendrobium huoshanense.] Thesis. Pp. 27-28. College of Food Science and Biotechnology Engineering, Hefei University of Technology, Hefei 2009. [In Chinese]

Wang K., He Z.: Alginate-konjac glucomannan-chitosan beads as controlled release matrix. - Int. J. Pharm. 244: 117-126, 2002. 
Wang L.H., Wang W., Zhou Q., Huang X.H.: Combined effects of lanthanum (III) chloride and acid rain on photosynthetic parameters in rice. - Chemosphere 112: 355-361, 2014.

Yang Q., Li Y., Wang L. et al.: Effect of lanthanum(III) on the production of ethylene and reactive oxygen species in soybean seedlings exposed to the enhanced ultraviolet-B radiation. Ecotox. Environ. Safe. 104: 152-159, 2014.

Yuan X., Wang Q., Zhao B., Wang Y.: Improved cell growth and total flavonoids of Saussurea medusa on solid culture medium supplemented with rare earth elements. - Biotechnol. Lett. 24: 1889-1892, 2002.

Yuan Y.J, Hu Z.D.: [Effect of rare earth elements on plant cell culture of Catharanthus roseus.] - Chin. Rare Earth 14: 30-34, 1993. [In Chinese]

Zhang C., Li Q., Zhang M. et al.: Effects of rare earth elements on growth and metabolism of medicinal plants. - Acta Pharm. Sin. B 3: 20-24, 2013

Zhang F., Hu H., Wang L. et al.: Effects of rare earth and acid rain pollution on plant chloroplast ATP synthase and element contents at different growth stages. - Chemosphere 194: 441-449, 2018

Zhang Y., Xie B., Gan X.: Advance in the applications of konjac glucomannan and its derivatives. - Carbohydr. Polym. 60: 27-31, 2005.

Zhao L., Zhang F.S., Zhang J.: Chemical properties of rare earth elements in typical medical waste incinerator ashes in China. J. Hazard. Mater. 158: 465-470, 2008

Zhou J., Fang L., Li X. et al.: Jasmonic acid (JA) acts as a signal molecule in $\mathrm{LaCl}_{3}$-induced baicalin synthesis in Scutellaria baicalensis seedlings. - Biol. Trace Elem. Res. 148: 392-395, 2012.

Zhou J., Zhang J., Guo L.P. et al.: [Effects of lanthanum on leaf photosynthesis and artemisinin accumulation in Artemisia annua.] - Chin. Trad. Herb Drug. 41: 1371-1374, 2010. [In Chinese]

(C) The authors. This is an open access article distributed under the terms of the Creative Commons BY-NC-ND Licence. 